\title{
A Dinâmica de Colaborações OpenStreetMap e sua Relação com as Atividades de Uso e Ocupação do Solo: um Estudo Segundo Zoneamento de Curitiba
}

\author{
The Dynamics of OpenStreetMap Collaborations and their Relationship to Land Use and \\ Occupation Activities: a Study According to Curitiba Zoning
}

Caio dos Anjos Paiva ${ }^{1}$ e Silvana Philippi Camboim ${ }^{2}$

1 Universidade Federal do Paraná, Departamento de Geomática, Curitiba, Brasil. E-mail: anjospaiva@gmail.com ORCID: https://orcid.org/0000-0002-1798-5307

2 Universidade Federal do Paraná, Departamento de Geomática, Curitiba, Brasil. E-mail: silvanacamboim@gmail.com ORCID: https://orcid.org/0000-0003-3557-5341

Resumo: Em regiões com défict ou restrição de acesso a dados espaciais oficiais, conhecer a qualidade dos dados colaborativos permite minimizar a falta de informação espacial. Admitindo como parâmetro de qualidade dos dados colaborativos a chamada Inteligência Espacial Coletiva, o presente artigo verifica a dependência entre a dinâmica das colaborações na plataforma OpenStreetMap e a aglomeração de pessoas. Para tal assumiu duas vertentes como influenciadoras dessa aglomeração: à derivada das atividades econômicas e a aglomeração derivada do local onde as pessoas resindem. Identificado essa dependência, foi possível estipular variáveis de qualidade para os dados colaborativos quando esses são qualificados em função da Inteligência Espacial Coletiva.

Palavras-chave: Mapeamento colaborativo. Inteligência Espacial Coletiva. OpenStreetMap.

Abstract: In developing countries, such as Brazil, the official mapping deficit is common. Knowing the quality of information on collaborative mapping platforms would minimize the lack of spatial data. Admitting the so-called Collective Spatial Intelligence as a parameter of collaborative data quality, this article aimed to verify the dependence between the dynamics of collaborations in the OpenStreetMap platform and the crowding of people. It has been assumed that agglomeration derives from the economic activities of a region and the place where people reside. Identifying the dependence, it was possible to stipulate quality variables for the collaborative data, when these are qualified according to Collective Spatial Intelligence.

Keywords: Collaborative mapping. Collective space intelligence. OpenStreetMap.

\section{INTRODUÇÃO}

Com a eclosão da Web 2.0 e a crescente utilização de tecnologias como o GPS e facilidades em se obter imagens de alta resolução, a informação espacial que tradicionalmente era produzida apenas por técnicos especialistas passou a ser gerada, também, por indivíduos sem conhecimento formal em cartografia (BRAVO; SLUTER, 2015). Assim, usuários comuns passaram a produzir e disponibilizar esse tipo de informação em plataformas de mapeamento colaborativo e mídias digitais (HECHT et al., 2013).

Apesar de não produzidos por técnicas e métodos vinculados a padrões clássicos de mapeamento, os dados gerados nestas plataformas trazem vantagens que despertam o interesse de diversos setores da sociedade. Entre elas destacam-se: os aspectos restritivos dos dados oficiais; aspectos financeiros; nível de atualização e potencial semântico dos dados colaborativos (BARRON; NEIS; ZIPF, 2014; NAPOLITANO; MOONEY, 2014). Em contrapartida, a heterogeneidade das colaborações dificulta a classificação da Informação Geográfica Voluntária (VGI) segundo padrões convencionais de qualidade (TOUYA; BRANDO-ESCOBAR, 2013). Devido a isso, embora tais dados estejam se ampliando nas diversas plataformas existentes, fica evidente que qualidade VGI é a principal questão a ser tratada quando se pretende utilizar esses dados como informação 
espacial de referência.

Conforme Mullen et al. (2015), a compreensão das características qualitativas dos dados colaborativos ainda não é completamente entendida. Isso porque diferente de um mapeamento convencional, os dados espaciais presentes nas mídias colaborativas não atendem normativas e padrões rígidos de qualidade em seu processo de geração. É difícil fixar, tanto uma precisão posicional quanto semântica para os dados.

Como forma de traçar um panorama de qualidade, grande parte das pesquisas que buscam retratar a confiabilidade VGI utilizam métodos comparativos (BARRON; NEIS; ZIPF, 2013). Nesse caso, dados espaciais oficiais considerados confiáveis são utilizados como base para que se determine a qualidade dos dados colaborativos.

Entretanto, em regiões em que os dados advindos de mapeamentos oficiais são escassos ou restritos, como é o caso de países em desenvolvimento como o Brasil, em que apenas 5\% de todo o território possui recobrimento na escala 1:25.000 (SLUTER et al., 2018), a análise da qualidade VGI por métricas comparativas se torna inviável. Devido a isso, novos métodos, indicadores e propostas de visualização da confiabilidade da informação voluntária devem ser estudados (BARRON; NEIS; ZIPF, 2014).

Nesse escopo, muitas linhas de pesquisa atribuem a chamada Inteligência Espacial Coletiva (IEC) um importante norteador de confiabilidade da informação espacial disponível nas mídias digitais (GOODCHILD; LI, 2012; HAKLAY et al., 2010; SPIELMAN, 2014). Segundo esses autores, a qualidade VGI possui relação com a capacidade de um grupo de indivíduos em corrigir os erros gerados por outros indivíduos. Em geral, os estudos se baseiam na denominada Lei de Linus. Voltada ao desenvolvimento de softwares a partir da abertura de códigos à comunidade de programadores colaboradores, a lei coloca que uma vez que os códigos de um software são examinados por diferentes pessoas, a presença de erros se evidencia (RAYMOND, 2001). Com isso, a existência de bugs tende a diminuir, garantindo sua eficácia e credibilidade.

No contexto do mapeamento colaborativo, a Lei de Linus remete ao fato de que há uma relação direta entre a qualidade dos dados e a quantidade de indivíduos participantes dos processos de geração de informação geoespacial. Quão mais uma área é mapeada e editada, maior sua confiabilidade.

Diante desses estudos, Camboim et al. (2015) buscaram verificar a existência de uma correlação da completude e atualização da informação disponível na plataforma OSM (OpenStreetMap) e variáveis econômicas e de desenvolvimento para o caso brasileiro. Para países em desenvolvimento, em que é comum a falta de uma base cartográfica oficial que sirva como referência para comparações, o estudo apresentou uma possibilidade de verificação da qualidade VGI sem a necessidade da existência de uma base de referência.

Admitindo como parâmetro de qualidade dos dados colaborativos a já conceituada IEC, o presente estudo busca verificar sua correlação com algumas variáveis pré-consideradas como influenciadoras da dinâmica de colaborações na plataforma OpenStreetMap. Tais variáveis correspondem a aglomeração de pessoas, seja ela derivada das atividades econômicas de uma região ou da densidade populacional e de domicílios.

Para que a análise das correlações fosse possível, foi preciso quantificar, além das referidas variáveis, a supracitada IEC. Essa quantificação se deu segundo instrumento de ordenamento das cidades brasileiras, ou seja, do zoneamento de um município utilizado como caso de estudo. Uma vez que o zoneamento apresenta a divisão dos municípios conforme atividades e usos do solo predominantes em distintas áreas, a confirmação da correlação entre as variáveis permitiu classificar regiões de maior ou menor confiabilidade de dados colaborativos, quando estas são avaliadas em função da IEC.

\section{DEFINIÇÃO DO CASO DE ESTUDO}

A definição de um caso de estudo se baseou nos insumos disponíveis para realização da metodologia, bem como no ordenamento da região foco de avaliação segundo seu zoneamento. No Brasil entende-se por zoneamento a divisão das cidades com vistas a atribuir diferentes usos e ocupação para distintas áreas. Essa divisão busca uma melhor utilização do espaço de acordo com o sistema viário, a topografia e a infraestrutura existente (OLIANI, 2015).

Quem rege o zoneamento são os municípios, a partir de suas leis municipais. Diante disso, e devido a heterogeneidade de usos do solo observada em distintas áreas, a região escolhida para aplicação da metodologia 
corresponde ao município de Curitiba, no estado do Paraná, Brasil (figura 1).

Figura 1 - Localização da área de estudo.

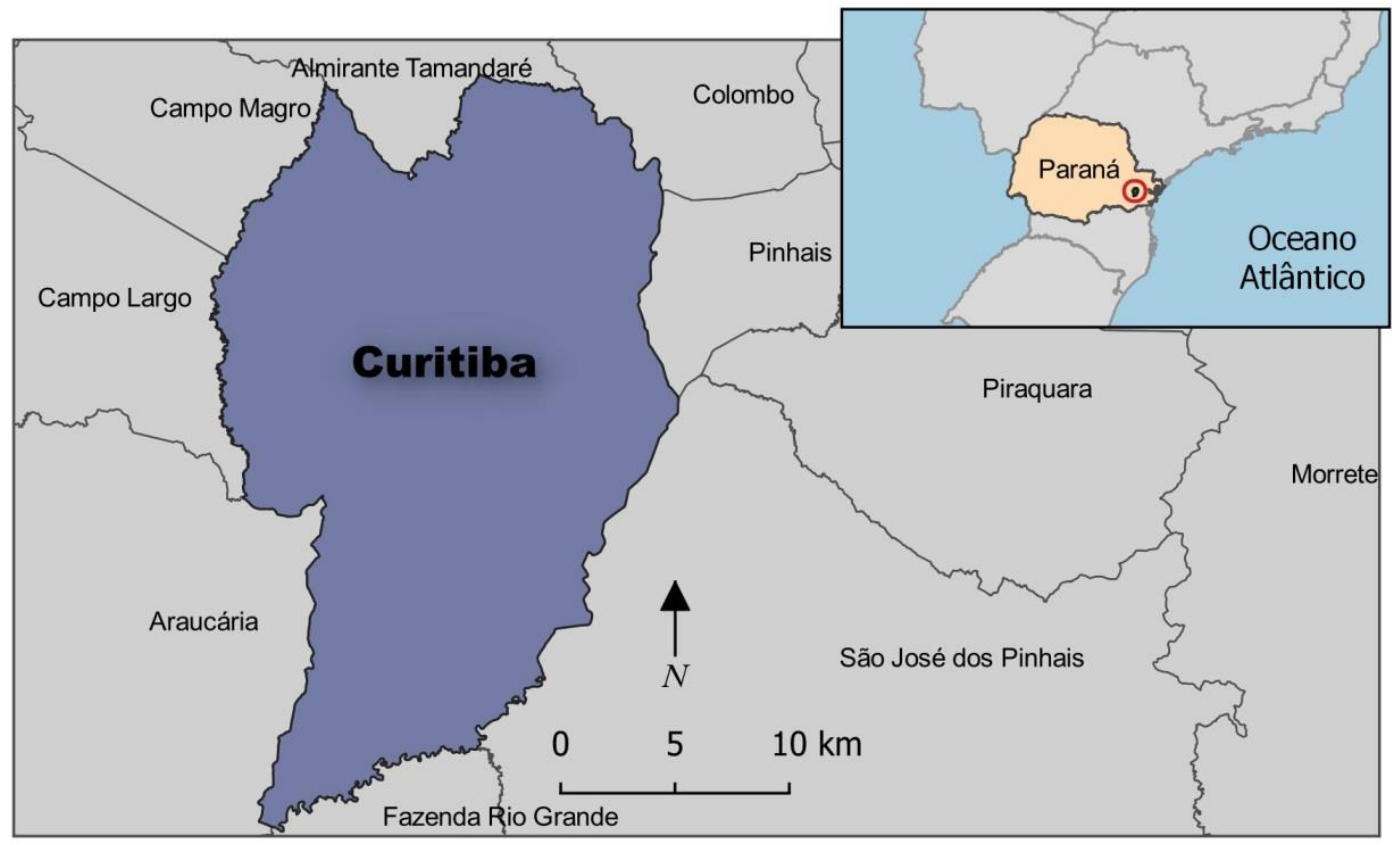

Fonte: Os autores (2021).

Segundo Lei municipal $N^{\circ}$ 9.800/2000 que discorre sobre o uso e ocupação do solo, a divisão do território curitibano se dá em zonas e setores, tendo como objetivo orientar e ordenar o crescimento da cidade. Essa organização é importante para as análises, pois segundo a Lei de Zoneamento, toda Curitiba é considerada urbana. Tão $\operatorname{logo}$, devido a predominância econômica de setores secundário e terciário na cidade o deslocamento dos habitantes se dá principalmente das zonas residenciais para aquelas com maior concentração de atividades econômicas (IPARDES, 2019).

Quanto a divisão do território, Curitiba é segmentada em dez grupos principais. Esses são subdivididos conforme predominância de uso já existente ou propensão projetada para a área. O Quadro 1 apresenta a descrição dos diferentes grupos, subgrupos e usos e ocupação do solo no município de Curitiba.

Quadro 1 - Disposição dos Grupos, subgrupos e usos e ocupação do solo segundo Lei Municipal 9080/2000.

\begin{tabular}{|c|c|c|}
\hline Grupo & Uso e Ocupação & Subgrupo \\
\hline $\begin{array}{l}\text { Zona } \\
\text { Central }\end{array}$ & $\begin{array}{l}\text { Centro tradicional da cidade, destinado } \\
\text { principalmente para atividades consideradas } \\
\text { de caráter urbano. }\end{array}$ & --- \\
\hline $\begin{array}{l}\text { Zonas } \\
\text { Residenciais }\end{array}$ & $\begin{array}{l}\text { Uso predominante residencial. Subdivide-se } \\
\text { segundo suas características de intensidade } \\
\text { populacional e padrão construtivo. }\end{array}$ & $\begin{array}{l}\text { Zona Residencial: de Ocupação Controlada; } \\
\text { Residencial (1,2, } 3 \text { e 4); Batel; Mercês; Alto } \\
\text { da Glória; Santa Felicidade; Umbará; } \\
\text { Passaúna. }\end{array}$ \\
\hline $\begin{array}{c}\text { Zonas de } \\
\text { Serviço }\end{array}$ & $\begin{array}{l}\text { Áreas de ligação e geradoras de tráfego pesado } \\
\text { ao longo de rodovias. }\end{array}$ & $\begin{array}{l}\text { Zona de Serviço 1; Zona de Serviço 2; Zona } \\
\text { Especial de Serviços. }\end{array}$ \\
\hline $\begin{array}{l}\text { Zonas de } \\
\text { Transição }\end{array}$ & Áreas limítrofes à zoneamentos conflitantes. & $\begin{array}{l}\text { Zona de Transição: da Av. Mal. Floriano } \\
\text { Peixoto; Nova Curitiba; BR-116. }\end{array}$ \\
\hline $\begin{array}{l}\text { Zonas } \\
\text { Industriais }\end{array}$ & $\begin{array}{l}\text { Destinadas à implantação de atividades } \\
\text { industriais de grande porte. }\end{array}$ & --- \\
\hline $\begin{array}{l}\text { Zonas de uso } \\
\text { misto }\end{array}$ & $\begin{array}{l}\text { Áreas com média densidade habitacional, } \\
\text { destinadas ao apoio às zonas industriais. }\end{array}$ & --- \\
\hline
\end{tabular}




\begin{tabular}{|c|c|c|}
\hline Grupo & Uso e Ocupação & Subgrupo \\
\hline $\begin{array}{l}\text { Zonas } \\
\text { Especiais }\end{array}$ & $\begin{array}{l}\text { Espaços físicos cuja ordenação se destina a } \\
\text { grandes usos institucionais. }\end{array}$ & $\begin{array}{l}\text { Zona Especial: Educacional; Desportiva; } \\
\text { Militar. }\end{array}$ \\
\hline $\begin{array}{c}\text { Zona de } \\
\text { Contenção }\end{array}$ & $\begin{array}{l}\text { Áreas periféricas de caráter residencial, } \\
\text { voltadas a preservação e manutenção de suas } \\
\text { características naturais. }\end{array}$ & --- \\
\hline $\begin{array}{l}\text { Setores } \\
\text { Especiais }\end{array}$ & $\begin{array}{l}\text { Compreendem áreas para as quais são } \\
\text { estabelecidas ordenações especiais de uso e } \\
\text { ocupação do solo, condicionadas às suas } \\
\text { características locacionais, funcionais ou de } \\
\text { ocupação urbanística, já existentes ou } \\
\text { projetadas e aos objetivos e diretrizes de } \\
\text { ocupação da cidade. }\end{array}$ & $\begin{array}{l}\text { Setor Especial: Conector; Centro Cívico; } \\
\text { Sistema Viário Básico; Histórico; Pref. de } \\
\text { Pedestres; Comercial do Umbará; Comercial } \\
\text { de Santa Felicidade; Nova Curitiba; } \\
\text { Institucional; Pontos Panorâmicos; Habitação } \\
\text { de Interesse Social; Linhão do Emprego; Pólo } \\
\text { de Software; Ocupação Integrada; Especial de } \\
\text { Áreas Verdes; Anel de Conservação Sanitário- } \\
\text { Ambiental; Estrutural; Eixos de Adensamento. }\end{array}$ \\
\hline $\begin{array}{l}\text { Proteção } \\
\text { Ambiental }\end{array}$ & Manutenção das características naturais & --- \\
\hline
\end{tabular}

Fonte: Os autores (2021).

Para o presente estudo é importante que as áreas avaliadas sejam agrupadas considerando como critério a aglomeração de pessoas. Diante disso, a partir do exposto no Quadro 1 e das especificações contidas nos quadros anexos da Lei 9800/2000, que determinam os parâmetros de uso e ocupação do solo para cada zona ou setor, algumas observações se deram.

Os subgrupos Centro Cívico e Centro Histórico, apesar de pertencerem ao grupo dos Setores Especiais, possuem características de carater urbano setorial. Não apenas a localização, mas a predominância de atividades, conforme Quadro I e Quadro XXXIII do referido anexo, denotam a essas áreas semelhanças que permitem agrupá-los junto a Zona Central.

Os subgrupos Nova Curitiba e Habitação de Interesse Social do grupo Setores Especiais; os subgrupos do grupo Zona de Transição; bem como o grupo Zonas de Uso Misto (Quadros XIV, XVI, XVIII, XXXVI e XL), possuem como principal parâmetro de uso e ocupação o fato de serem áreas destinadas principalmente a habitação unifamiliar. Nestas, são permitidos a instalação de comércio e serviço vicinal para o atendimento da população local. Podem então, ser estudadas como áreas residenciais.

Outra observação diz respeito aos principais eixos de ligação da cidade. Os subgrupos do Setor Especial: Setores Estruturais; Conectores; Linhão do Emprego e Eixos de Adensamento, são caracterizados por serem faixas de ligação entre bairros e entre bairros e a região central da cidade. São em geral, áreas de média-alta densidade habitacional, dimensionadas sobre corredores comerciais, de serviços e transporte, tendo como suporte o sistema viário estrutural da cidade (CURITIBA, 2000). Devido a tais peculiaridades, podem receber uma classificação única.

Já o grupo Zonas Residenciais, apesar de prioritariamente habitacional, possui grandes diferenças quanto a densidade habitacional permitida. Segundo Lei 9800/2000, o subgrupo Residencial 4 (ZR-4) permite a construção de empreendimentos com até seis pavimentos e é possível a utilização comercial desde que a área não ultrapasse $200 \mathrm{~m}^{2}$. Além disso, é permitido a verticalização para oito ou dez pavimentos por meio da compra de potencial construtivo. Inseridos nos limites destas áreas estão os subgrupos Batel, Mercês e Alto da Glória, pequenas áreas que acabam se fundindo às ZR-4, podendo ser estudadas em um único bloco.

Por fim, tem-se as áreas de influência da antiga BR-116, que corta o município no sentido Norte-Sul. Em virtude dos conflitos entre o tráfego urbano e de carga gerado pela rodovia, medidas foram tomadas para a reestruturação desse corredor. Com a aprovação da Lei Municipal $\mathrm{N}^{\circ} 13.909 / 2011$, que estabelece as diretrizes para construção do novo eixo de integração intramunicipal e metropolitano, adequando o sistema viário, o uso e ocupação do solo nas referidas áreas foi reestruturado. Denominada atualmente de Operação Urbana Consorciada Linha Verde, as áreas deste subgrupo podem ser agrupadas, também, como uma só.

Do exposto, o mapa subsequente (figura 2) apresenta a divisão estipulada para os experimentos do estudo. Essa organização leva em conta a lei de zoneamento de Curitiba, agrupando subgrupos do zoneamento 
conforme semelhanças verificadas em seus parâmetros de uso e ocupação.

Figura 2 - Organização das Áreas de Estudo.
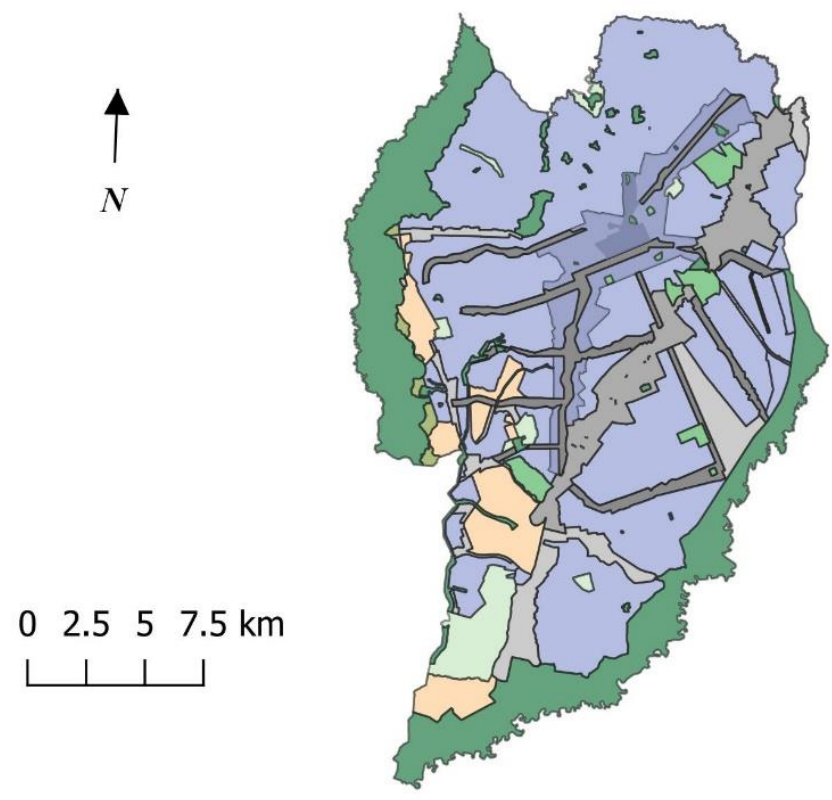

Zonas e Setores

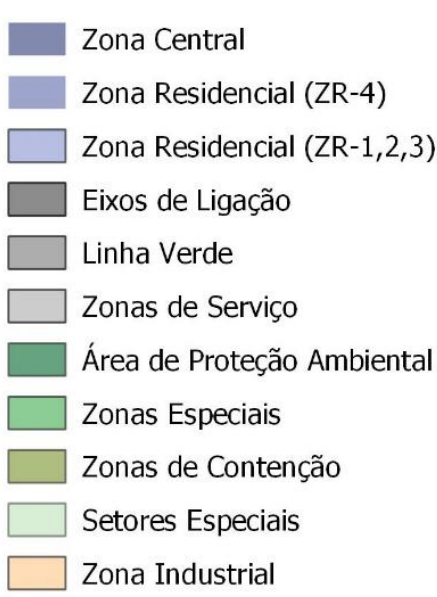

Fonte: Os autores (2021).

\section{METODOLOGIA E RESULTADOS}

Visando apresentar um panorama geral do estudo, o fluxograma metodológico (figura 3) desenha a sequência dos procedimentos realizados. Nele temos: a definição das variáveis representativas da qualidade VGI; a escolha da plataforma de mapeamento utilizada para exprimir a dinâmica de colaborações; a escolha do estudo de caso, com o agrupamento das áreas em função das atividades permitidas pelo zoneamento; e a extração dos dados a partir de diferentes fontes.

Figura 3 - Fluxograma metodológico.

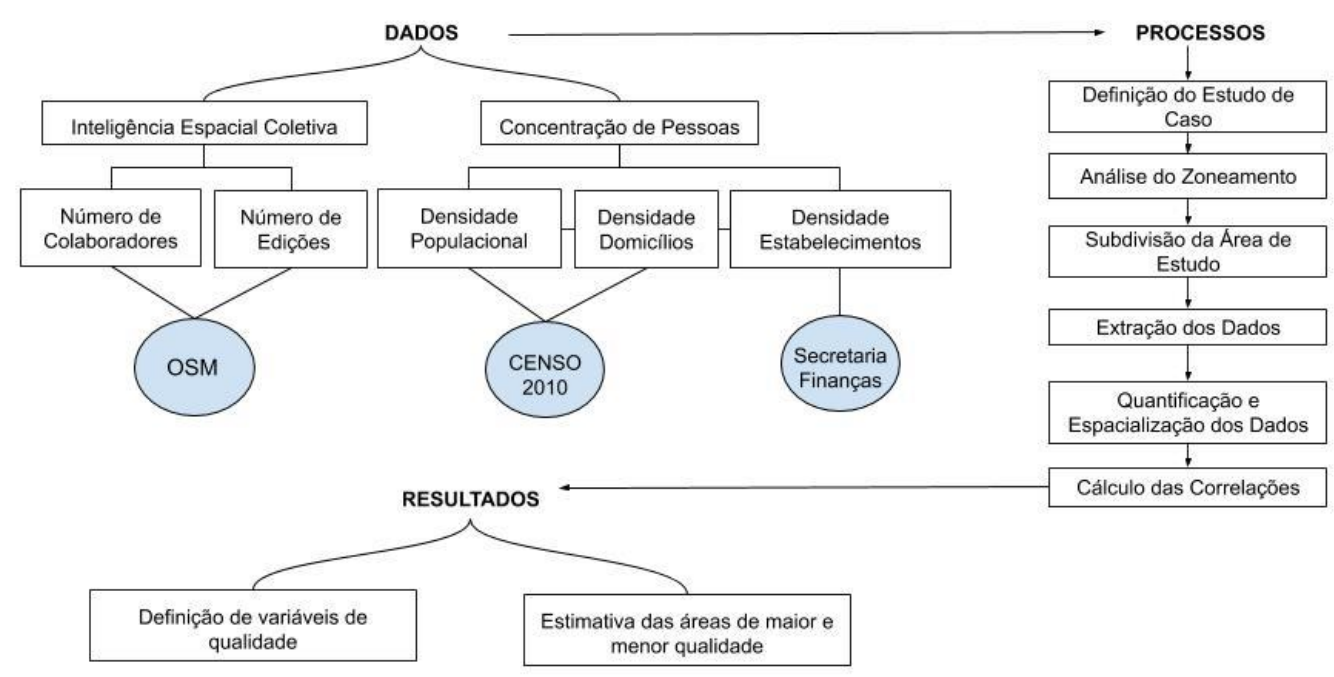

Fonte: Os autores (2021).

Do OSM foram retiradas as quantidades que expressam a Inteligência Espacial Coletiva. Essas dizem respeito ao número de colaboradores e de edições realizadas em uma determinada área na plataforma. Da base de dados do IBGE foram extraídos, a partir da grade estatística do Censo 2010, que divide as áreas urbanas do território brasileiro em quadrículas de $200 \mathrm{X} 200 \mathrm{~m}$, a população total e de domicílios por quadrícula. Isso 
permitiu verificar a concentração de pessoas em função do cálculo da densidade populacional e de domicílios.

Já a verificação da aglomeração de pessoas como conexa às atividades econômicas, se deu pela análise dos dados da Secretaria de Finanças de Curitiba. Uma vez que ela disponibiliza os endereços de todos os estabelecimentos com registro formal na cidade, foi possível estabelecer uma relação destes com a mencionada aglomeração.

Resumidamente computou-se para cada área do zoneamento de Curitiba, valores referentes ao número de colaboradores e de edições realizadas na plataforma OSM; um valor de densidade populacional e de domicílios; e uma quantidade de estabelecimentos comerciais.

\subsection{Quantificação e Espacialização da Inteligência Espacial Coletiva}

Como citado, os insumos para retratar a IEC foram retirados da plataforma OpenStreetMap. Para tal, recorreu-se a criação de um algoritmo computacional. Este algoritmo, gerado em linguagem de programação Python propiciou a leitura e transferência das informações de interesse, presentes nos históricos das feições do OSM, para um banco de dados espacial estruturado em um Sistema de Gerenciamento de banco de Dados (PostgreSQL). Para facilitar a leitura e vinculação dos valores lidos às zonas e setores, dividiu-se inicialmente o território curitibano em quadrículas, sendo estas, correspondentes à grade estatística do Censo 2010, disponibilizada pelo IBGE (figura 4).

Figura 4 - Divisão do território em quadrículas.

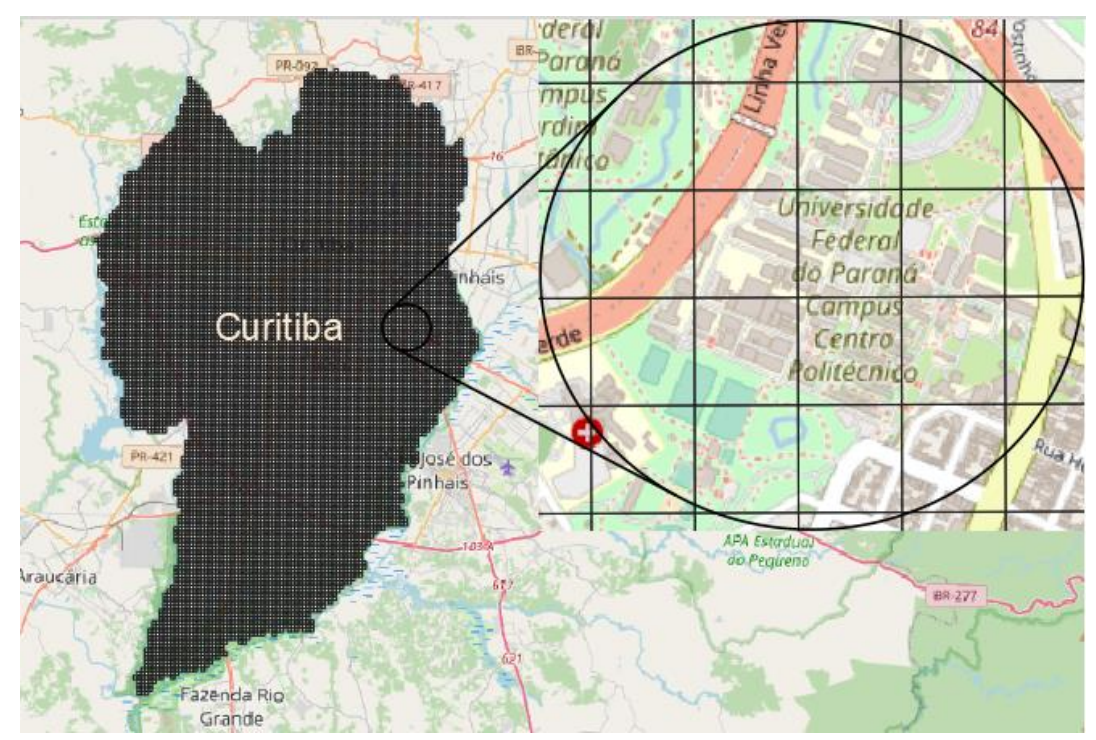

Fonte: Os autores (2021).

Como sequência da divisão, o algoritmo baixa em um arquivo .xml informações referentes a todos os elementos OSM (nós, caminhos e relações) de uma quadrícula. Tais informações dizem respeito a identificação, posição e diferenciação dos elementos em elementos que possuem e não possuem tag.

Visto que caminhos e relações são elementos formados por nós, o algoritmo percorre o arquivo criado, identificando quais são válidos para serem considerados nos processos de extração do número de colaboradores e edições. Assim, exclui da contabilização elementos que não possuem tags, ou seja, os nós que apenas compõe as feições cartográficas.

Na sequência é executada uma query (consulta) no histórico dos elementos validados, de forma a retirar destes o número de colaboradores que realizaram algum tipo de edição nas feições, bem como a quantidade de edições nelas efetuadas. O resultado é salvo em um arquivo temporário e a soma das quantidades é computada para a quadrícula cuja consulta esteja sendo executada.

Definido essa soma, o banco de dados é preenchido, atribuindo o número de colaboradores que atuaram em uma quadrícula específica, bem como o respectivo número de edições. O diagrama a seguir (figura 5) apresenta a sequência de operações do algoritmo para preenchimento do banco de dados.

Após computar os referidos valores para cada quadrícula, foi preciso atribuir essas quantidades às áreas 
de interesse. Isso se deu interceptando as quadrículas aos polígonos do zoneamento.

Figura 5 - Sequência para extração de informação do OSM.

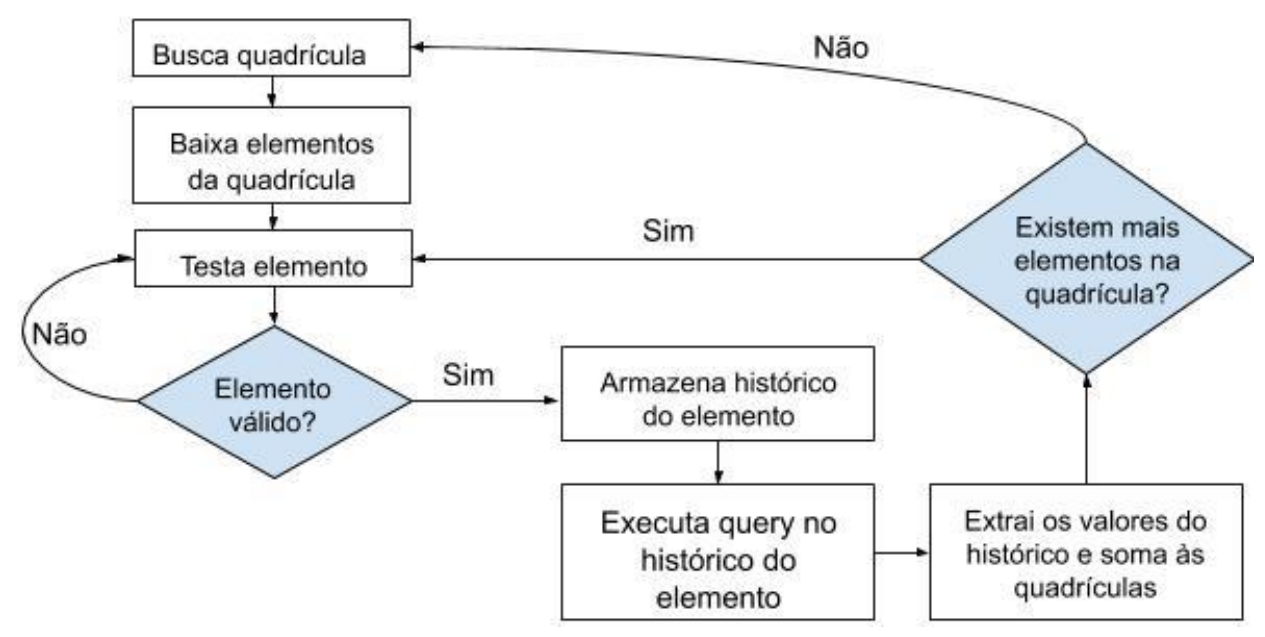

Fonte: Os autores (2021).

\subsection{Definição e Espacialização da Concentração de Pessoas}

Para retratar a concentração de pessoas, duas vertentes foram abordadas: as aglomerações devido às atividades econômicas da região e aquela percebida pela densidade populacional e de domicílios. No primeiro caso, admitindo que as atividades econômicas de uma localidade são condicionantes para a aglomeração de pessoas, a variável estipulada como representativa dessa aglomeração corresponde a densidade de estabelecimentos com registro formal na cidade de Curitiba. Já a densidade populacional e de domicílios buscou retratar a aglomeração de pessoas em função do local onde reside a população.

Para atribuir a densidade de estabelecimentos às zonas e setores recorreu-se a um processo de geolocalização dos endereços de estabelecimetos comerciais fornecidos pela Secretaria Municipal de Finanças de Curitiba. Após o processo, a sobreposição dos endereços sobre os polígonos do zoneamento permitiu a contagem desses dentro de cada polígono (figura 6).

Figura 6 - Vinculação do número de estabelecimentos às zonas e setores.

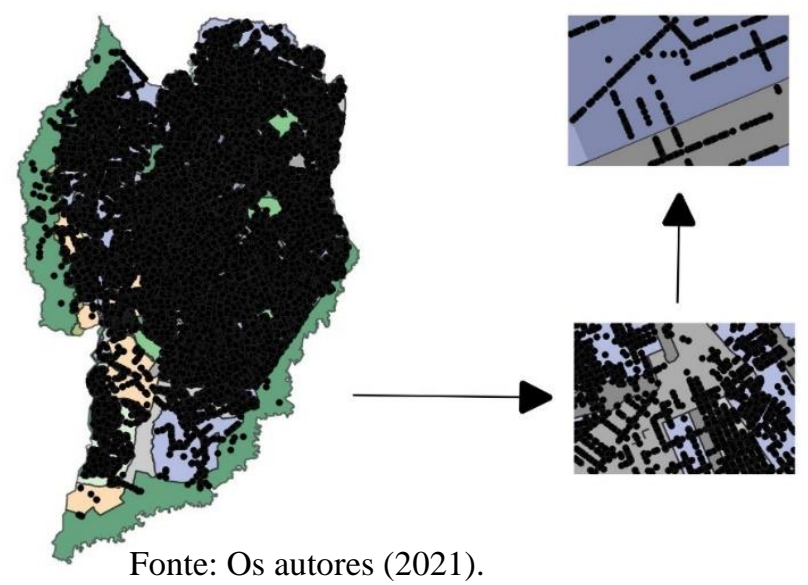

Já para atribuir os valores de densidade populacional e de domicílios para as zonas ou setores, uma vez que a grade estatística do IBGE detém a informação referente ao número de habitantes e de domicílios por quadrícula, recorreu-se a esta para vincular a informação aos polígonos do zoneamento. Conforme mostra a figura 7, realizando a interseção das zonas e setores (A) com a grade (B), foi possível obter uma camada de pequenos fragmentos cujas áreas foram calculadas (C). Esses fragmentos passaram a possuir como informação, tanto a identificação da zona ou setor, como a densidade populacional e de domicílios das quadrículas. 
Figura 7 - Vinculação do número da densidade populacional e de domicílios às zonas e setores.

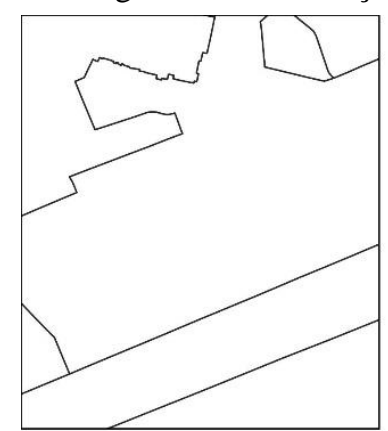

$\mathrm{A}$

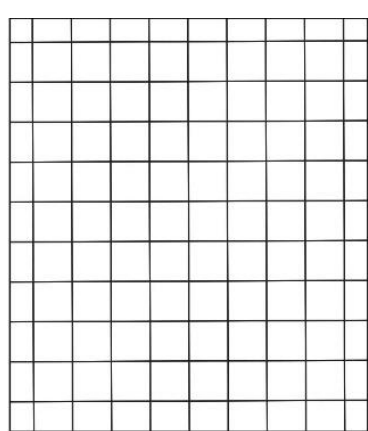

$\mathrm{B}$

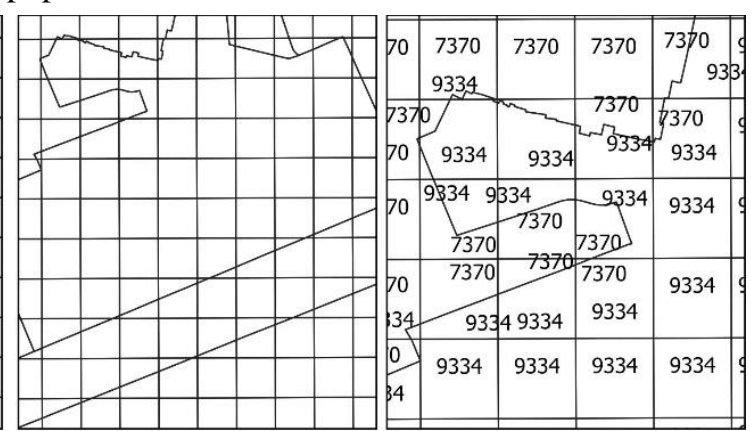

$\mathrm{C}$
$\mathrm{D}$

Fonte: Os autores (2021).

Como havia a possibilidade de uma zona ou setor se vincular a diferentes densidades populacionais e de domicílios (D), foram calculados, para cada um, uma densidade única. Esta, considerou os valores de densidade dos fragmentos pertencentes às diferentes zonas ou setores, bem como as áreas dos fragmentos e setores. As equações 1 e 2 demonstram o enunciado, sendo que tal ponderação se deu em função do valor de área dos fragmentos.

$$
\begin{gathered}
\mathrm{D}=\sum(d i * f i) \\
\mathrm{fi}=\frac{\text { área do fragmento }}{\text { área da zona ou setor }}
\end{gathered}
$$

Em que:

a) D: Densidade populacional ou de domicílios calculada para cada zona ou setor;

b) di: Densidade populacional ou de domicílios dos fragmentos;

c) fi: Fator de ponderação calculado em função da área dos fragmentos.

\subsection{Influência da aglomeração de pessoas na dinâmica de colaborações}

O cálculo da correlação entre a aglomeração de pessoas e as variáveis representativas da IEC buscou delinear a influência da primeira na dinâmica das colaborações na plataforma OpenStreetMap. Para fins de análise calculou-se o coeficiente de correlação de Pearson entre as variáveis. Conforme Moore (2007), o coeficiente de Pearson mensura a direção e o grau da relação linear entre duas variáveis quantitativas. Dessa forma, são considerados valores abaixo de 0,40 como insignificantes ou de baixa correlação; entre 0,40 e 0,69 de moderada correlação e; acima de 0,70 como de forte correlação.

Além do cálculo de correlação entre os valores de densidade, ou seja, valores que medem a concentração das variáveis dentro de cada zona ou setor, foram calculadas as correlações a partir dos valores absolutos. Neste último caso considerou-se os valores brutos retirados das fontes de dados.

Como pode ser visto na tabela 1 , ao analisar os valores absolutos das variáveis verificou-se a influência do número de domicílios (V4) e de habitantes (V5), bem como da quantidade de estabelecimentos (V6) por zona ou setor, na dinâmica de edições (V2 e V3). Os altos valores positivos encontrados, todos acima de 0,90, permitem pressupor que as colaborações na plataforma OSM, para as diferentes áreas do zoneamento crescem à medida que o número de habitantes, domicílios e estabelecimentos comerciais aumenta.

Apesar do forte indício de correlação, um cuidado deve ser tomado ao se considerar como verdade a afirmação. Uma vez que as zonas e setores possuem valores de áreas distintos, é possível que estes tenham sido determinantes para as altas correlações encontradas. Isso fica evidente, pois conforme a tabela, existe forte correlação entre a variável Área (V1) e as demais variáveis analisadas a partir de seus valores absolutos (V2, V3, V4, V5 e V6). 
Diante disso, a confirmação da influência da concentração de pessoas na dinâmica de colaborações se deu pelo cálculo das correlações das densidades das variáveis. Isentas da influência dos valores de área, tanto o número de colaboradores (V7), como de edições (V8) por km², possuem forte correlação com a densidade de estabelecimentos (V11). Os valores acima de 0,90 confirmam que o fato de uma zona ou setor possuir intensa atividade econômica, é um fator determinante para o aumento das colaborações.

É interessante ressaltar que a aglomeração de pessoas, derivada das atividades econômicas influência em maior grau a dinâmica de colaborações, do que a aglomeração derivada do local onde as pessoas residem. Isso se evidencia devido a correlação encontra entre a densidade de colaboradores (V7) e de edições (V8), com a densidade de domicílios (V9).

O mesmo ocorre na comparação com a densidade populacional (V10). Ao compará-la com a densidade de edições (V8), apesar de alta, o valor atinge apenas 0,71. Já com a densidade de colaboradores (V7), a correlação é avaliada como moderada, assumindo o valor de 0,66 . A descrição que segue visa detalhar as variáveis utilizadas no cálculo dos correlações apresentadas na tabela 1.

Área em km² $^{2}$ V1); Número de colaboradores por zona ou setor (V2); Número de edições por zona ou setor (V3); Número de domicílios por zona ou setor (V4); População por zona ou setor (V5); Número de estabelecimentos por zona ou setor (V6); Número de colaboradores por $\mathrm{km}^{2}$ (V7); Número de edições por km² (V8); Número de domicílios por $\mathrm{km}^{2}$ (V9); Número de habitantes por $\mathrm{km}^{2}$ (V10); Número de estabelecimentos por $\mathrm{km}^{2}(\mathrm{~V} 11)$.

Tabela 1- Correlações entre as variáveis representativas da concentração de pessoas e a dinâmica de colaborações.

\begin{tabular}{c|c|c|c|c|c|c|c|c|c|c|c}
\hline & $V 1$ & $V 2$ & $V 3$ & $V 4$ & $V 5$ & $V 6$ & $V 7$ & $V 8$ & $V 9$ & $V 10$ & $V 11$ \\
\hline V1 & 1,00 & & & & & & & & & & \\
\hline V2 & 0,96 & 1,00 & & & & & & & & & \\
\hline V3 & 0,93 & 0,99 & 1,00 & & & & & & & & \\
\hline V4 & 0,86 & 0,95 & 0,96 & 1,00 & & & & & & & \\
\hline V5 & 0,88 & 0,95 & 0,95 & 1,00 & 1,00 & & & & & & \\
\hline V6 & 0,83 & 0,94 & 0,95 & 0,98 & 0,97 & 1,00 & & & & & \\
\hline V7 & 0,24 & 0,08 & 0,04 & 0,03 & 0,07 & 0,12 & 1,00 & & & & \\
\hline V8 & 0,27 & 0,10 & 0,04 & 0,03 & 0,07 & 0,11 & 0,99 & 1,00 & & & \\
\hline V9 & 0,14 & 0,01 & 0,08 & 0,20 & 0,17 & 0,28 & 0,82 & 0,86 & 1,00 & & \\
\hline V10 & 0,09 & 0,06 & 0,13 & 0,30 & 0,27 & 0,33 & 0,66 & 0,71 & 0,97 & 1,00 & \\
\hline V11 & 0,19 & 0,09 & 0,07 & 0,02 & 0,04 & 0,11 & 0,94 & 0,93 & 0,85 & 0,69 & 1,00 \\
\hline
\end{tabular}

Fonte: Os autores (2021).

Identificado a dependência entre a dinâmica de colaborações e as variáveis representativas da aglomeração de pessoas, realizou-se a classificação e comparação desta. Nesta etapa a intenção foi apresentar visualmente as áreas em que as variáveis se equivalem. Os mapas a seguir (figuras 8 a 13) apontam as zonas e setores em que há maiores e menores concentração de pessoas, contrapondo essas áreas aquelas em que há maior e menor intensidade de colaborações espaciais. Os gráficos associados as representações demonstram no eixo das ordenadas, a variação na dinâmica de colaborações em função dos valores representativos da aglomeração de pessoas, expostos no eixo das abcissas. 
Figura 8 - Número de domicílios e de colaboradores por $\mathrm{km}^{2}$.

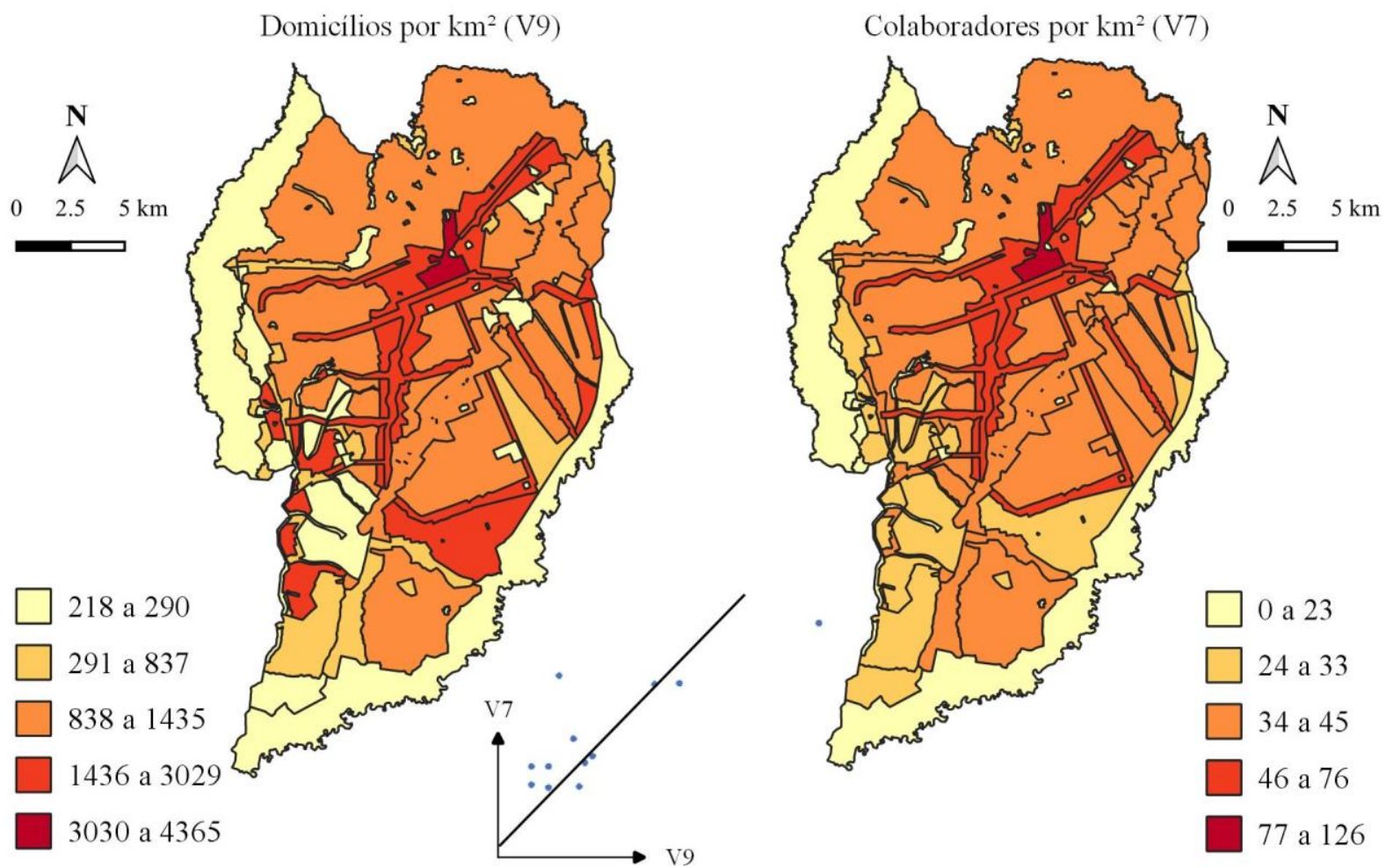

Fonte: Os autores (2021).

Figura 9 - Número de habitantes e de colaboradores por $\mathrm{km}^{2}$.

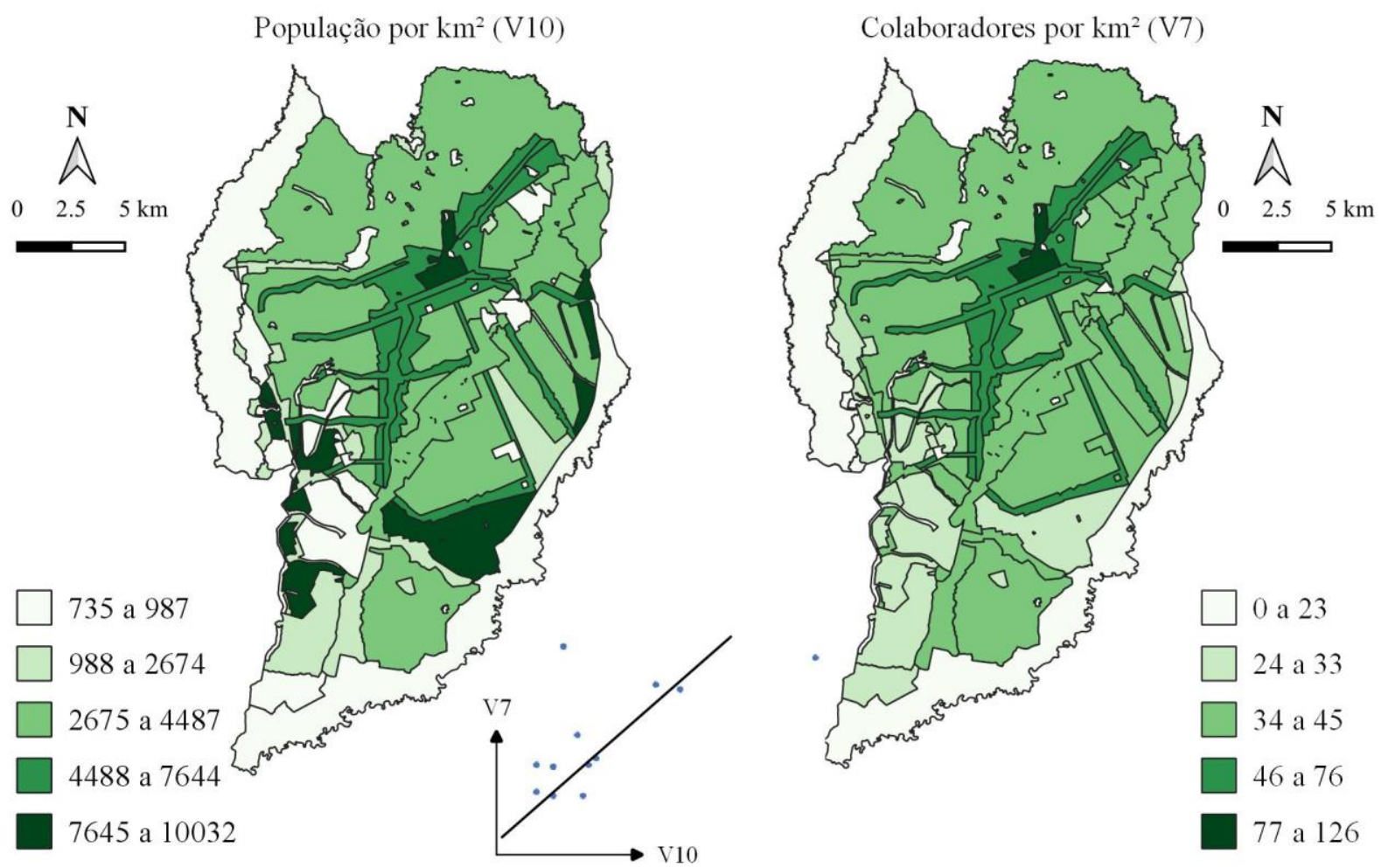

Fonte: Os autores (2021). 
Figura 10 - Número de estabelecimentos e de colaboradores por $\mathrm{km}^{2}$.

Estabelecimentos por $\mathrm{km}^{2}$ (V11) Colaboradores por $\mathrm{km}^{2}$ (V7)

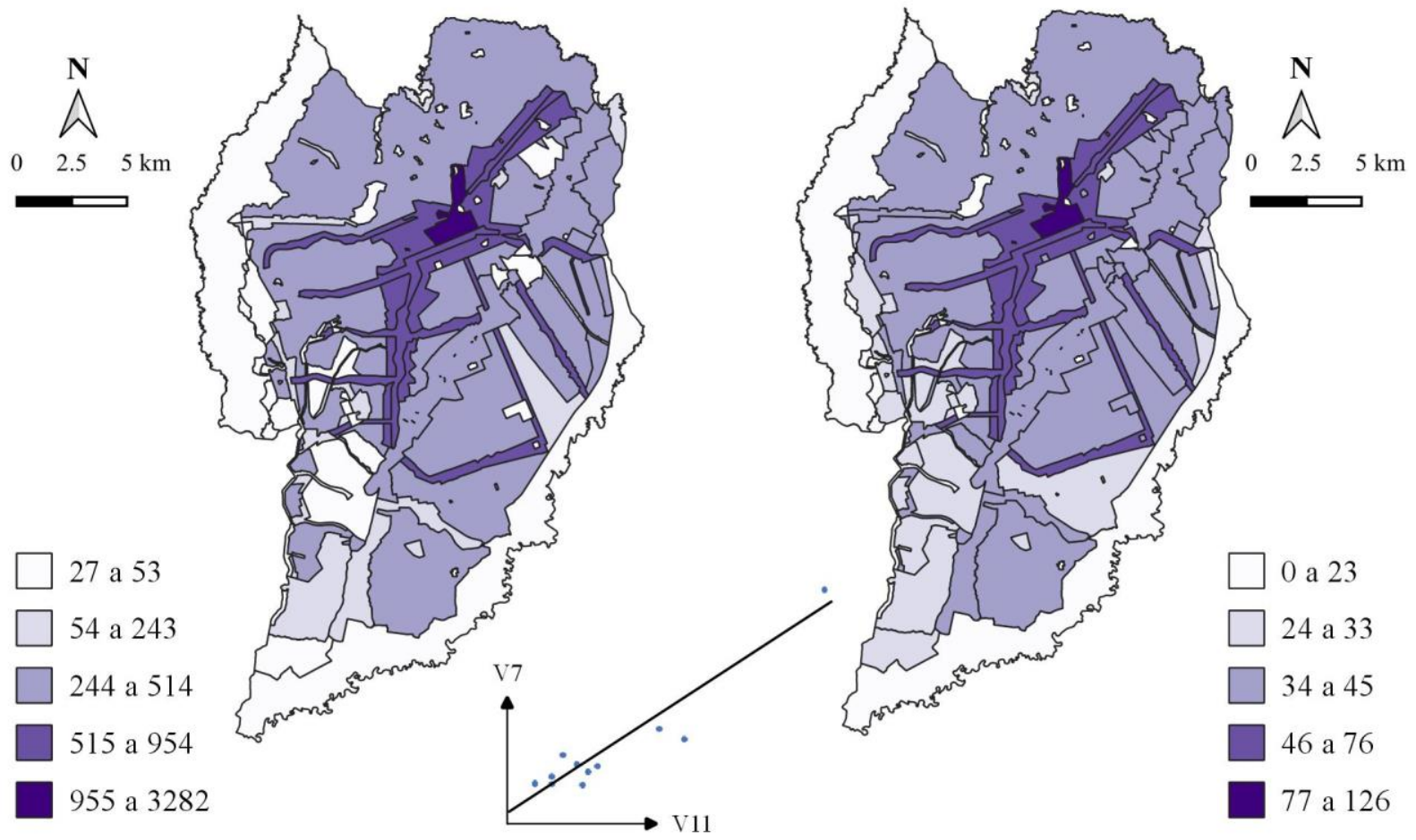

Fonte: Os autores (2021).

Figura 11 - Número de domicílios e de edições por $\mathrm{km}^{2}$.

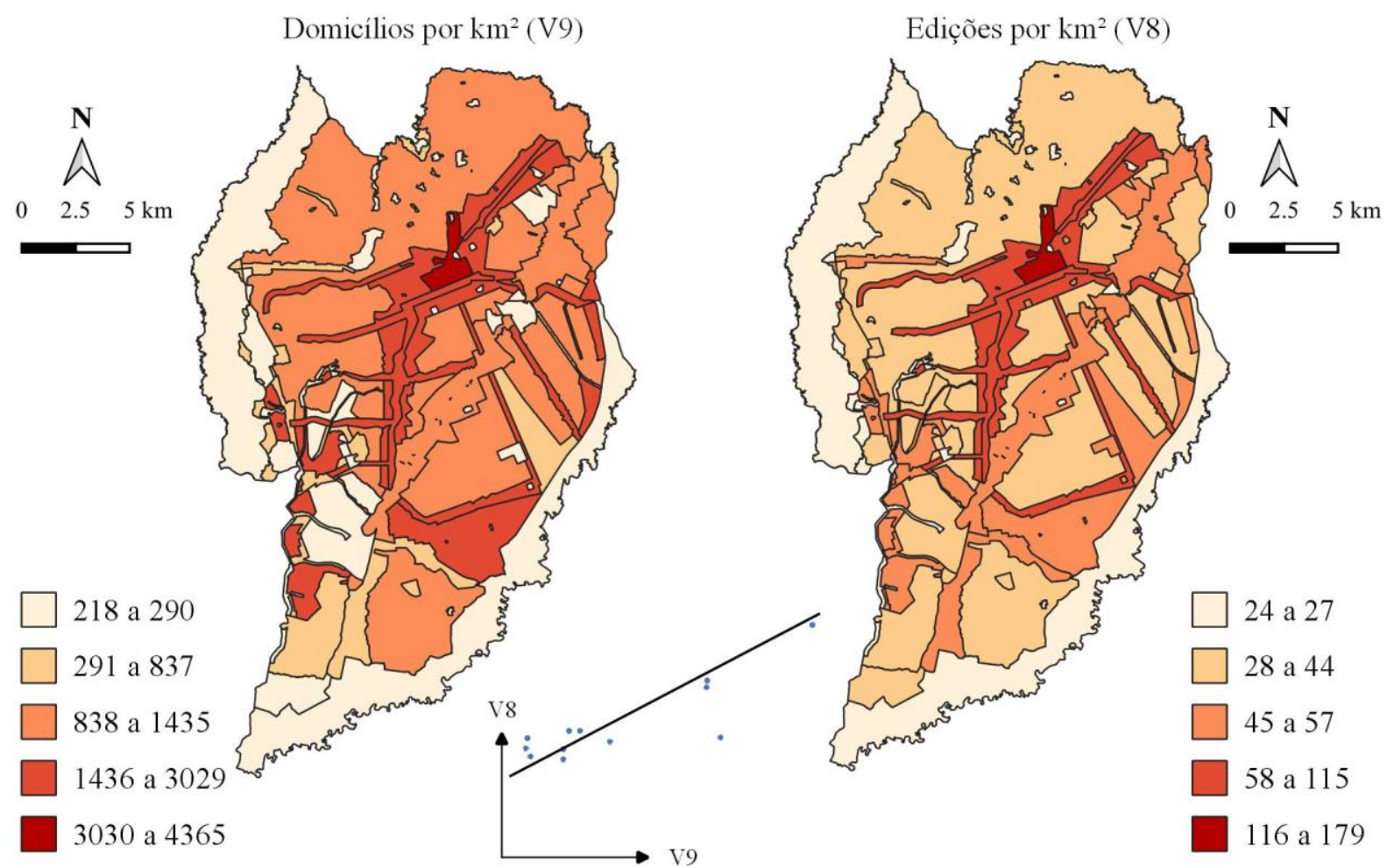

Fonte: Os autores (2021). 
Figura 12 - Número de habitantes e de edições por $\mathrm{km}^{2}$.

Polulação por $\mathrm{km}^{2}(\mathrm{~V} 10)$

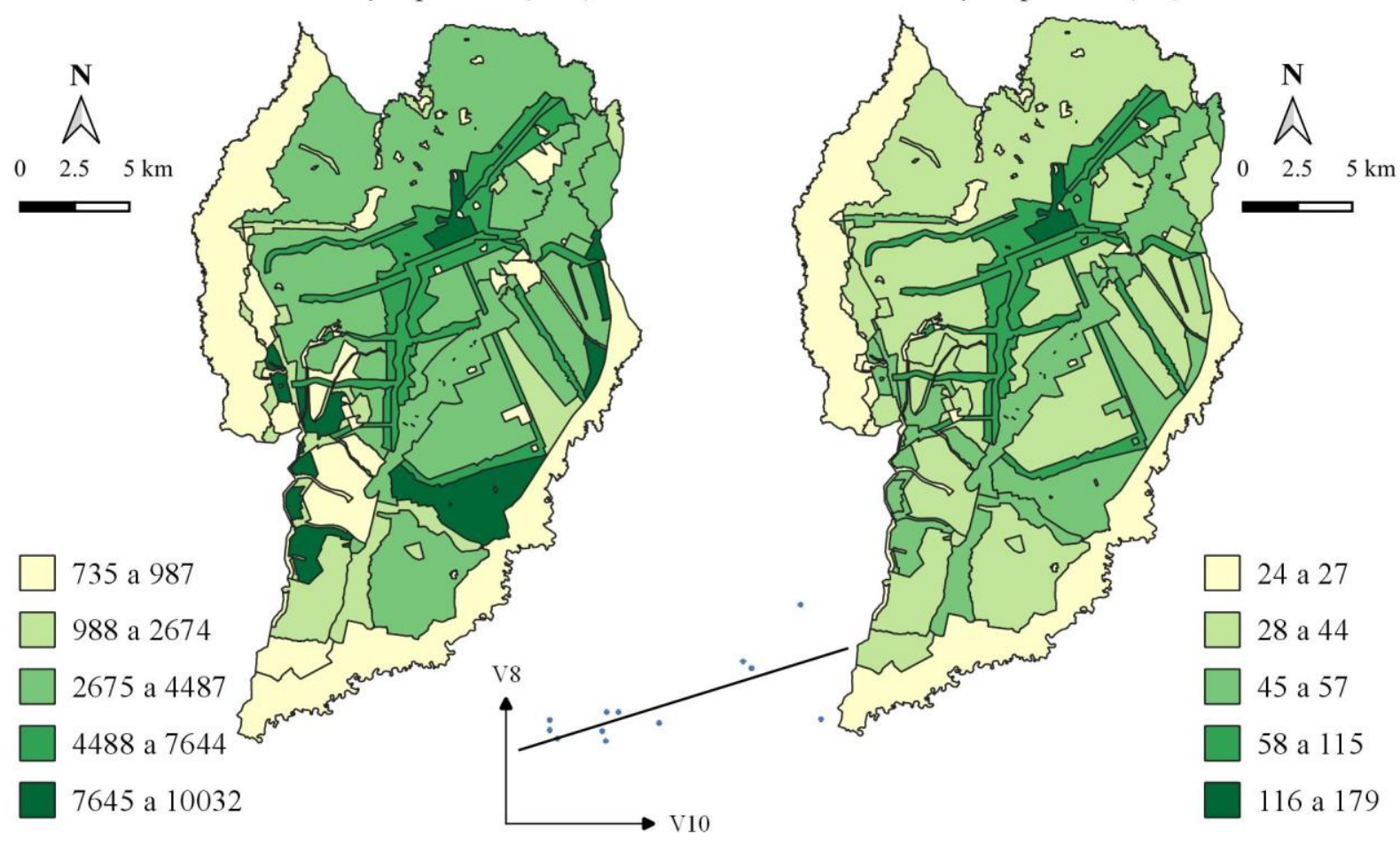

Fonte: Os autores (2021).

Figura 13 - Número de estabelecimentos e de edições por km².

Estabelecimentos por $\mathrm{km}^{2}$ (V11)

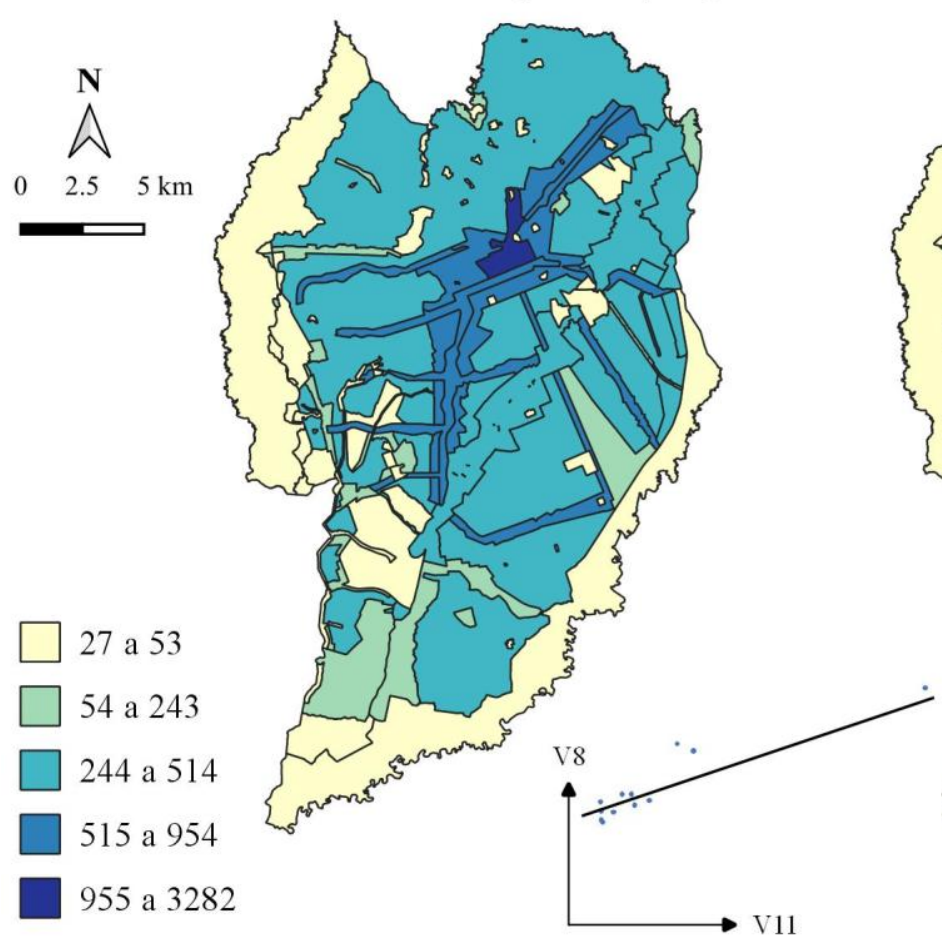

Edições por $\mathrm{km}^{2}$ (V8)

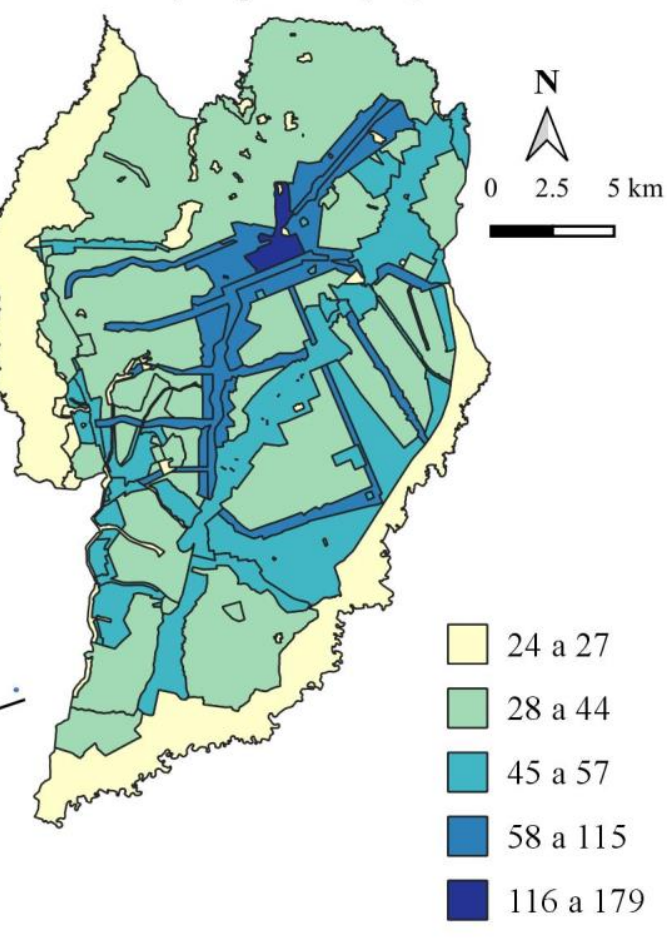

Fonte: Os autores (2021). 


\section{CONCLUSÃO}

O objetivo deste artigo foi apresentar a dependência da dinâmica de colaborações espaciais na plataforma OpenStreetMap, frente a concentração de pessoas, seja ela derivada das atividades econômicas de uma região ou da localidade em que as pessoas residem. A divisão do território escolhido como caso de estudo a partir do seu zoneamento permitiu comparar diferentes áreas em função das suas atividades e usos predominantes do solo. Visto que a hipótese inicial era a de que áreas economicamente ativas detinham dinâmica de colaborações mais acentuada do que áreas com pouca atividade, foi possível afirmar que as zonas e setores de cunho comercial são os que possuem maior volume de edições na plataforma OpenStreetMap.

Outro aspecto do município estudado, é o de que algumas áreas com volume acentuado de colaborações correspondem, também, aos principais eixos de ligação da cidade. Isso comprova que um dos parâmetros para avaliar a dinâmica de colaborações é o seu aumento em função da ramificação do sistema viários das cidades, conforme já estudado por diversos autores (ATHER, 2009; KOUNADI, 2009; SEHRA; SINGH; RAI, 2017; WOLF et al., 2011).

Por fazer parte de um estudo mais abrangente, que tem por objetivo definir variáveis intrínsecas de qualidade para os dados colaborativos, a principal colaboração para estudos futuros se deu nesse aspecto, ou seja, identificar possíveis variáveis de qualidade. Foi possível definir como parâmetros adicionais de qualidade espacial para os dados colaborativos, a concentração de estabelecimentos comerciais e a densidade populacional e de domicílios.

Uma vez que se admitiu como parâmetro de qualidade para os dados colaborativos a (IEC), é importante ressaltar que o presente artigo apenas define possíveis variáveis de qualidade, já que a IEC não foi testada como variável capaz de retratar a confiabilidade VGI. Assim, devido às altas correlações encontradas, admitese que, em regiões em que a predominância econômica se molda pelos setores secundário e terciário, como é o caso de Curitiba, áreas de intensa atividade econômica podem indicar que os dados colaborativos nela existentes possuem maior confiabilidade. Com ressalva, novamente, que essa confiabilidade se dá quando é avaliada em função da Inteligência Espacial Coletiva.

\section{Contribuição dos Autores}

Caio dos Anjos Paiva projetou e executou o experimento, escreveu o manuscrito e foi responsável pela contextualização e revisão da literatura. Silvana Philippi Camboim orientou o desenvolvimento do projeto e as etapas de execução do experimento, estruturou e revisou o manuscrito.

\section{Conflitos de Interesse}

Os autores declaram que não há conflitos de interesse.

\section{Referências}

ATHER, A. A quality analysis of Openstreetmap data. 89 f. M.Eng. Dissertation. University College London, 2009.

BARRON, C.; NEIS, P.; ZIPF, A. Towards Intrinsic Quality Analysis of OpenStreetMap Datasets. In: International Workshop on Action and Interaction in Volunteered Geographic Information (ACTIVITY), 2013, Leuven, Belgium. Edited by Peter Mooney, and Karl Rehrl, pp. 43-48.

BARRON, C.; NEIS, P.; ZIPF, A. A Comprehensive Framework for Intrinsic OpenStreetMap Quality Analysis. Transactions in GIS, v. 18, n. 6, p. 877-895, 2014.

BRAVO, J. V. M.; SLUTER, C. R. O Problema Da Qualidade De Dados Espaciais na Era das Informações Geográficas Voluntárias. Boletim de Ciências Geodésicas, vol. 21, pp. 56-73. Curitiba, 2015.

CAMBOIM, S. P.; MEZA BRAVO, J. V.; SLUTER, C. R. An investigation into the completeness of, and the updates to, OpenStreetMap data in a heterogeneous area in Brazil. ISPRS International Journal of Geo- 
Information, v. 4, n. 3, p. 1366-1388, 2015. DOI. 10.3390/ijgi4031366

CURITIBA. Lei Municipal no 9080 de 03 de janeiro de 2000. Dispõe sobre o Zoneamento, Uso e Ocupação do Solo no Município de Curitiba e dá outras providências.

CURITIBA. Decreto no 190 de 03 de abril de 2000. Dispõe sobre os critérios de uso e ocupação do Plano Massa nos Setores Especiais Estruturais, e dá outras providências.

CURITIBA. Decreto no 190 de 03 de abril de 2000. Dispõe sobre os critérios de uso e ocupação do Plano Massa nos Setores.

CURITIBA. Lei Municipal no 13.909 de 19 de dezembro de 2011. Aprova a Operação Urbana Consorciada Linha Verde - OUC-LV, estabelece diretrizes urbanísticas para a área de influência da atual Linha Verde.

GOODCHILD, M. F.; LI, L. Assuring the quality of volunteered geographic information. Elsevier Spatial Statistics, v. 1, p. 110-120, 2012. DOI. 10.1016/j.spasta.2012.03.002

HAKLAY, M. et al. How many volunteers does it take to map an area well? the validity of Linus' law to volunteered geographic information. Cartographic Journal, v. 47, n. 4, p. 315-322, 2010. DOI. $10.1179 / 000870410 X 12911304958827$

HECHT, R.; KUNZE, C.; HAHMANN, S. Measuring completeness of building footprints in openstreetmap over space and time. ISPRS International Journal of Geo-Information, v. 2, n. 4, p. 1066-1091, 2013. DOI. 10.3390/ijgi2041066

INSTITUTO PARANAENSE DE DESENVOLVIMENTO ECONÔMICO E SOCIAL (IPARDES). Caderno estatístico do município de curitiba. 2019. Disponível em: $<$ http://www.ipardes.gov.br/cadernos/MontaCadPdf1.php?Municipio=80000\&btOk=ok $>$. Acesso em: 10 dez. 2020.

KOUNADI, O. Assessing the quality of OpenStreetMap data. $80 \mathrm{f}$. Master's thesis. University College of London, 2009.

MOORE, D. S. The Basic Practice of Statistics. New York: W. H. Freeman, 2007.

MULLEN, W. F. et al. Assessing the impact of demographic characteristics on spatial error in volunteered geographic information features. GeoJournal, v. 80, n. 4, p. 587-605, 2015. DOI: 10.1007/s10708-0149564-8

NAPOLITANO, M.; MOONEY, AssessingMVP OSM: A Tool to Identify Areas of High Quality Contributor Activity in OpenStreetMap. The Bulletin of the Society of Cartographers. v. 45, p. 9802-9806, 2014.

OLIANI, L. O. Noções De Cadastro Territorial Multifinalitário - CTM. Série de Cadernos Técnicos da Agenda Parlamentar - CREA-PR, p. 35, 2015.

RAYMOND, E. S. The Cathedral and the Bazaar. Massachusetts: O'Reilly Media, 2001.

SEHRA, S. S.; SINGH, J.; RAI, H. S. Assessing openstreetmap data using intrinsic quality indicators: An extension to the QGIS processing toolbox. Future Internet, v. 9, n. 2, 2017. DOI: 10.3390/fi9020015

SLUTER, C. R. et al. A Proposal for Topographic Map Symbols for Large-Scale Maps of Urban Areas in Brazil. Cartographic Journal, v. 55, n. 4, p. 362-377, 2018. DOI: 10.1080/00087041.2018.1549307

SPIELMAN, S. E. Spatial collective intelligence? credibility, accuracy, and volunteered geographic information. Cartography and Geographic Information Science, v. 41, n. 2, p. 115-124, 2014. DOI: 10.1080/15230406.2013.874200.

TOUYA, G.; BRANDO-ESCOBAR, C. Detecting Level of Detail Inconsistencies in VGI Datasets. Cartographica The International Journal for Geographic Information and Geovisualization, v. 
48, n. 2, p. 134-143, 2013. DOI: 10.3138/carto.48.2.1836

WOLF, E. B. et al. OpenStreetMap Collaborative Prototype, Phase One. U.S. Geological Survey. Virginia, 2011.

\section{Biografia do autor principal}

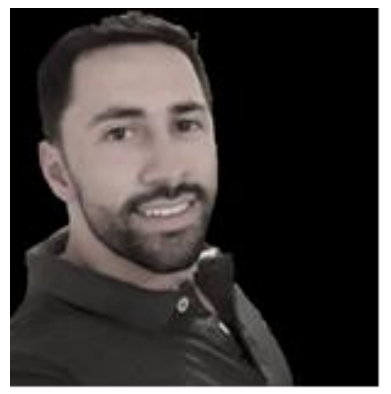

Caio dos Anjos Paiva, Curitiba - PR - Brasil. Possui graduação em Engenharia Cartográfica e de Agrimensura (2014) e mestrado em Ciências Geodésicas (2016) pela Universidade Federal do Paraná. É doutorando do Programa de Pós Graduação em Ciências Geodésicas da mesma universidade, onde atua como professor do Departamento de Geomática. Tem experiência nas áreas de Levantamentos Geodésicos e Topografia, Cartografia e SIG. Sua atual pesquisa tem ênfase em Mapeamento Colaborativo.

Esta obra está licenciada com uma Licença Creative Commons Atribuição 4.0 Internacional - CC BY. Esta licença permite que outros distribuam, remixem, adaptem e criem a partir do seu trabalho, mesmo para fins comerciais, desde que lhe atribuam o devido crédito pela criação original. 